\title{
CORUMBÁ-MS: O RETORNO DA MIGRAÇÃO INDOCUMENTADA DE HAITIANOS NO BRASIL
}

\author{
Corumbá-MS: the return of undocumented haitian migration in Brazil
}

Corumbá-MS: el regreso de la migración indocumentada de haitianos en Brasil

Alex Dias de Jesus ${ }^{*}$

*Professor do Instituto Federal de Educação, Ciência e Tecnologia do Piauí (IFPI), doutor em Geografia pela Universidade Federal da Grande Dourados (UFGD) - alexdias@ifpi.edu.br

Recebido em 17/03/2020. Aceito para publicação em 17/03/2020

Versão online publicada em 05/05/2020 (http://seer.ufrgs.br/paraonde)

\section{Resumo:}

O permanente quadro de pobreza estrutural vigente no Haiti fez com que milhões de haitianos buscassem na migração alternativas para a melhoria das condições de vida. A partir de 2010, alguns países da América do Sul passaram a fazer parte dos destinos dos migrantes haitianos que, por meio de redes sociais, conectam os vários espaços dessa antiga e intensa mobilidade. Entretanto, as respostas à migração haitiana na América do Sul tem sido a implementação de políticas restritivas por parte dos governos dos países de destino e de trânsito. Especialmente no Chile, a partir de abril de 2018, um decreto promulgado pelo presidente Sebastián Piñera, dificultou a permanência e regularização dos haitianos no país. Diante disso, o presente artigo objetiva analisar a recente mobilidade internacional de haitianos que abandonam o Chile e ingressam de maneira indocumentada no Brasil através do município de Corumbá, no estado do Mato Grosso do Sul.

Palavras-chave: Haitianos. Migração indocumentada. Chile. Bolívia. Fronteira

\begin{abstract}
:
The permanent framework of structural poverty in Haiti has led millions of Haitians to seek alternatives to improving living conditions in migration. As of 2010, some South American countries have become part of the destiny of Haitian migrants who, through social networks, connect the various spaces of this ancient and intense mobility. However, the responses to Haitian migration in South America have been the implementation of restrictive policies by the governments of countries of destination and transit. Especially in Chile, as of April 2018, a decree promulgated by President Sebastián Piñera made it difficult for Haitians to stay and regularize in the country. Therefore, the present article aims to analyze the recent international mobility of Haitians who leave Chile and enter undocumented in Brazil through the municipality of Corumbá, in the state of Mato Grosso do Sul.
\end{abstract}

Keywords: Haitians. Undocumented migration. Chile. Bolivia. Border.

\section{Resumen:}

El permanente cuadro de pobreza estructural vigente en Haití ha hecho que millones de haitianos busquen en la migración alternativas para la mejora de las condiciones de vida. A partir de 2010, algunos países de América del Sur pasaron a formar parte de los destinos de los migrantes haitianos que, por medio de redes sociales, conectan los diversos espacios de esa antigua e intensa movilidad. Sin embargo, las respuestas a la migración haitiana en 


\begin{abstract}
América del Sur han sido la implementación de políticas restrictivas por parte de los gobiernos de los países de destino y de tránsito. Especialmente en Chile, a partir de abril de 2018, un decreto promulgado por el presidente Sebastián Piñera dificultó la permanencia y regularización de los haitianos en el país. En el presente artículo se pretende analizar la reciente movilidad internacional de haitianos que abandonan Chile e ingresan de manera indocumentada en Brasil a través del municipio de Corumbá, en el estado de Mato Grosso do Sul.
\end{abstract}

Palabras clave: Haití. Migración indocumentada. Chile. Bolivia. Frontera.

\title{
1. Introdução
}

Em março de 2010, veículos da imprensa local e nacional divulgaram a entrada de pequenos grupos de haitianos em território brasileiro, através da cidade de Corumbá, no estado do Mato Grosso do Sul, na fronteira com a Bolívia. Pouco tempo depois, essa rota foi praticamente desativada quando os haitianos passaram a ingressar no Brasil principalmente pelas fronteiras internacionais da região Norte do país. A articulação dos agentes de viagens e coiotes no Equador e Peru e as extorsões sofridas no território boliviano são alguns dos motivos para que a travessia pela Bolívia fosse evitada. Oito anos depois, mais uma vez de maneira inesperada, Corumbá volta a ser um local de entrada dessa migração e o Mato Grosso do Sul, um espaço de trânsito desses migrantes em direção ao Sul e Sudeste do país.

De maneira semelhante ao ocorrido em 2010, os haitianos chegam à fronteira sem o visto exigido pelas autoridades brasileiras. Inicialmente, o visto humanitário, regulamentado pela Portaria Interministerial $n^{\circ} 10$, de 6 de abril de 2018 e atualmente pela Portaria Interministerial $n^{\circ} 12$, de 20 de dezembro de 2019. Vindos do Chile, os haitianos ficam impossibilitados de solicitar o documento, tendo em vista que ele só pode ser concedido na Embaixada brasileira no Haiti ou àqueles que ingressaram no Brasil até a data de sua publicação. Agenciados por coiotes, em 2018, mais de 1.500 haitianos saíram do Chile, cruzaram o território boliviano em direção à Corumbá e, sem alternativa, passaram a solicitar refúgio junto à Polícia Federal brasileira ou receberam notificações para a regularização da situação migratória.

Em situação indocumentada na Bolívia, parte desses migrantes estão sendo alvo de extorsões e chegam ao Brasil sem recursos, o que os impede de seguir viagem rumo ao encontro de seus familiares e amigos em diversas cidades brasileiras. Os custos planejados quase sempre são excedidos, tendo em vista as incertezas do percurso. Por esse motivo, no mês de junho de 2018, centenas de haitianos encontravam-se em Corumbá impedidos de seguir viagem, alguns deles em situação de rua.

Diante disso, o presente trabalho teve como objetivos refletir sobre as causas da saída dos haitianos do Chile, o retorno da situação indocumentada dos haitianos no Brasil e as vulnerabilidades a que estão expostos no contexto de ampliação das medidas restritivas à mobilidade humana, muitas delas baseadas na securitização das migrações. Por outro, lançamos também o olhar sobre as estratégias de contornamento das barreiras impostas pelas legislações. Cada restrição implementada pelos governos provoca, por parte

ParaOnde!?, Porto Alegre, v.13, n.2, p.75-89, 2020.http://seer.ufrgs.br/paraonde Edição Especial - VII Seminário Internacional de Estudos Fronteriços 
dos migrantes, uma reação de atravessamento ou desvio. Uma espécie de "rota de fuga" é desenvolvida.

Considerando a atualidade da migração haitiana para o Brasil, estudos sobre o tema têm apontado importantes questões teóricas e tendências desse fluxo (HANDERSON, 2015; BAENINGER et al, 2016), mas as análises de cunho quantitativo são sempre parciais dada a intensa mobilidade dessa população. Diante disso, o uso de metodologias mistas nos estudos migratórios objetiva compensar eventuais falhas na aquisição de dados e informações. Por esse motivo, este estudo baseou-se em revisão bibliográfica e pesquisas de campo no município de Corumbá nos meses de março e agosto de 2018.

\section{A migração haitiana na América do Sul}

De acordo com informações de Handerson (2015), na América do Sul, a migração haitiana remonta à década de 1960, quando um empresário francês proprietário de uma fábrica de olhos essenciais no sul do Haiti levou um grupo de 12 haitianos para trabalhar em uma usina de exploração agrícola na Guiana Francesa. Dois anos depois, outros 56 haitianos foram trazidos pelo mesmo comerciante e trabalharam na agricultura voltada para a exportação. Essa migração cresceu até a média anual de entradas chegar a 2 mil pessoas entre os anos de 1980 a 1984 (CALMONT, 1993).

Com a necessidade de comprovação de um vínculo empregatício no departamento ultramarino francês, o Suriname se configurou, na década de 1970, como um importante espaço de trânsito e posteriormente de permanência, principalmente na capital Paramaribo onde os haitianos criaram bases de redes migratórias que foram sustentadas ao longo de décadas.

No cenário das discussões da Diretiva do Retorno na Comunidade Europeia, em 2009, o governo francês solicitou do governo do Suriname diminuição dos vistos para haitianos com o objetivo de controlar a entrada destes na Guiana Francesa. Desse modo, como estratégia de contornamento, outras rotas e redes começaram a surgir. É nesse contexto que se insere a entrada de haitianos por Tabatinga, Amazonas, a partir dos primeiros meses de 2010.

Na nova fase da migração haitiana, iniciada após o terremoto de 12 de janeiro de 2010, apesar do fluxo orientado para a Guiana Francesa, grupos expressivos tinham o Brasil como destino prioritário. A presença brasileira no comando da Missão das Nações Unidas para a Estabilização do Haiti (MINUSTAH), o crescimento da economia brasileira no início do século XXI e, posteriormente, a possibilidade de aquisição do visto humanitário, foram fatores que contribuíram para que o país se transformasse em um novo destino dessa migração.

A crise estrutural e humanitária no Haiti, e o contexto global de assimetria econômica e mundialização das migrações, entre outros processos, posicionou Brasil e Chile como destinos de referência para a população haitiana. Por sua parte, países como Equador e Peru constituem destinos de chegada e trânsito, respectivamente. De todo

ParaOnde!?, Porto Alegre, v.13, n.2, p.75-89, 2020.http://seer.ufrgs.br/paraonde Edição Especial - VII Seminário Internacional de Estudos Fronteriços 
modo, pequenas comunidades haitianas têm se estabelecido em ambos os países. As comunidades haitianas maiores na América do Sul assentaram-se no Brasil e Chile, com uma maior chegada nos últimos dois anos para este último, produto da crise socioeconômica da principal potência do subcontinente (PEDEMONTE et al, 2017, p. 10) [Tradução nossa].

Segundo a interpretação de Audebert (2017), a diversificação da migração internacional do Haiti entrou numa nova fase após o terremoto de 2010, incorporando novas rotas em diversos países da América Latina, mas em um sistema conectado com a América do Norte e Caribe. A articulação de forças geopolíticas, econômicas e ambientais reconfiguraram a migração haitiana nos últimos anos, tendo Brasil e Chile ocupado posições centrais na região, enquanto Argentina, Peru e Equador desempenham importantes posições intermediárias de chegada, trânsito e permanência.

No Equador, apesar de o início da migração haitiana ter sido registrado em meados dos anos 2000, os números eram pouco expressivos até 2008, quando o governo de Rafael Corrêa, por meio de Decreto Executivo, aboliu a necessidade de visto de turista para qualquer nacionalidade em 20 de junho daquele ano, permitindo ingressar e permanecer no país. Isso possibilitou que, dois anos mais tarde, o país se convertesse em porta de entrada dos haitianos na América do Sul.

Em virtude do terremoto, Corrêa publicou o Decreto Executivo no 248 , em fevereiro de 2010, permitindo a regularização do status migratório dos haitianos já residentes no país e a reunificação familiar. De acordo com Alarcón (2017), entre 2006 e 2015, as Unidades de Controle Migratório do Equador registraram mais de 55 mil entradas de haitianos no país. Como resultado da isenção do visto de turista, as entradas saltaram de 270 em 2008 para 1.257 em 2009 e voltaram a apresentar um grande crescimento entre 2012 e 2013, passando de 3.024 para 14.162, justamente em um período que a maior permanência passou a ser notada.

As cidades de Quito e Guayaquil funcionaram como importantes portas de entrada por estarem conectadas com voos internacionais provenientes do Caribe e da América Central. De lá, a maioria dos haitianos seguia viagem de ônibus para o Peru e depois para o Brasil. No final de 2013, o estudo de Pierrette Louijeste, citado por Carrera (2014), apontou que aproximadamente $95 \%$ de seus entrevistados haviam chegado enganados por redes de tráfico que funcionam tanto no Haiti quanto no Equador. $\mathrm{O}$ argumento mais comum utilizado era que poderiam ter estudos gratuitos e trabalho. Além da mudança na legislação, como apontamos, a economia dolarizada e a falsa ideia de que se pode acessar qualquer país da América Latina por via terrestre, fazem parte dos motivos que se escutam entre a população haitiana no Equador para que migrem até lá.

No Peru, a quase totalidade dos haitianos que lá estiveram entre os anos de 2010 e 2015 esteve associada ao trânsito para o Brasil e mais recentemente para o Chile. Desde o início, esse país configurou-se enquanto um espaço de passagem, com pouca permanência. As rotas utilizadas estavam associadas à presença de coiotes que articulavam o transporte desde 0

ParaOnde!?, Porto Alegre, v.13, n.2, p.75-89, 2020.http://seer.ufrgs.br/paraonde Edição Especial - VII Seminário Internacional de Estudos Fronteriços 
Equador até o Brasil. Em janeiro de 2012, diante da crescente migração pelo país, o governo peruano, através do Decreto Supremo № 001-2012, passou a exigir o visto de turista para os haitianos, justificando que seria por "razões de política migratória" (VÁSQUEZ, BUSSE e IZAGUIRRE, 2014). Essa medida estimulou ainda mais a atuação das redes de tráfico de pessoas e consequentemente, os abusos e extorsões ao longo do caminho.

As informações coletadas por Vásquez, Busse e Izaguirre (2014) indicaram que a expectativa da grande maioria dos haitianos que passaram pelo Peru foi chegar ao Brasil o mais rápido possível e quando ocorreram obstáculos para que isso se concretizasse, os migrantes apresentaram visível descontentamento. "Paradoxalmente, a maioria tinha conhecimentos muito imprecisos sobre como, onde e em que condições vivem seus familiares e amigos no Brasil" (VÁSQUEZ, BUSSE e IZAGUIRRE, 2014, p. 99) [Tradução nossa].

A partir de 2015, com o fechamento do abrigo de Brasileia, no estado brasileiro do Acre, com a disseminação de informações dos migrantes anteriores e com o aumento da concessão de vistos humanitários pela Embaixada brasileira em Porto Príncipe, a migração haitiana pelo Peru praticamente desapareceu.

$\mathrm{Na}$ Argentina, de acordo com Evangelista (2016), os haitianos são predominantemente jovens, homens, com ensino médio completo, mas sem experiencia profissional. Segundo a autora, a Dirección Nacional de Migraciones (DNM) da Argentina revelou que, entre o ano de 2010 e novembro de 2013, entraram 4.658 haitianos no país, mas alerta que muitos desses podem já ter saído. Também muitas outras chegadas ocorreram desde então. Apenas na cidade de Rosário vivem cerca de 2.500 haitianos que recentemente fundaram uma associação (BARRANDEGUY, 2017).

"Segundo dados revelados, a população haitiana que migra para a Argentina pertence à classe média, média-alta do Haiti. São jovens entre $20 \mathrm{e}$ 30 anos que desejam começar seus estudos universitários ou finalizá-los" (EVANGELISTA, 2016, p. 12) [Tradução nossa]. Entretanto, nos últimos anos, assim como em outros destinos, houve uma diversificação nessa configuração com a chegada de pessoas das áreas rurais e com pouco domínio do francês, alguns falantes apenas do creole, inclusive.

No Chile, assim como em outros países da América do Sul, a presença de haitianos era pequena antes do terremoto de 2010 e mesmo nos dois anos seguintes à catástrofe. Segundo informações de Pedemonte, Amode e Vásquez, (2017), desde 2012, o número de haitianos no país duplicou a cada ano e só no primeiro semestre de 2016, mais de 20.000 ingressaram indicando que se trata de uma migração muito recente. A desaceleração da economia brasileira e a consequente eliminação de postos de trabalho no Brasil contribuíram para que parte dos haitianos reorientassem seus projetos migratórios em outra direção. Porém, Villanueva (2014) também relaciona esse processo com a presença militar chilena no contexto da MINUSTAH.

ParaOnde!?, Porto Alegre, v.13, n.2, p.75-89, 2020.http://seer.ufrgs.br/paraonde Edição Especial - VII Seminário Internacional de Estudos Fronteriços 
A quase totalidade dos haitianos no Chile reside na capital Santiago e trata-se, predominantemente, de trabalhadores e estudantes homens, estando a maioria entre 15 e 44 anos (88\%), embora a presença feminina esteja aumentando como resultado do fortalecimento das redes familiares. A maioria está empregada com salários em torno do mínimo, nos setores de serviços, da construção civil e limpeza. Mesmo aqueles que possuem diploma de nível superior acabam desempenhando essas funções, tendo em vista as barreiras para a validação de seus diplomas (PEDEMONTE, AMODE e VÁSQUEZ, 2017).

No Brasil, os dados da Polícia Federal sistematizados no Sistema Nacional de Cadastro e Registro de Estrangeiros (SINCRE) apontam o total de 105.636 entradas de haitianos no país entre 2010 e 2018 sob diversos amparos legais, mas predominando o visto humanitário. Tal instrumento passou a ser concedido em 2012 por meio da Resolução Normativa 97 do Conselho Nacional de Imigração (CNIg) e posteriormente pela Resolução $102 / 2013$ do mesmo órgão. O visto serviu de base legal para a entrada de haitianos no país durante vários anos, mas em 6 de abril de 2018 o governo brasileiro implementou a Portaria Interministerial no 10 contendo restrições à migração haitiana. De acordo com o novo instrumento, apenas residentes no Haiti poderão solicitar acolhida humanitária e o visto é emitido exclusivamente na Embaixada brasileira de Porto Príncipe. Além disso, o prazo de validade da residência como acolhida humanitária passou de cinco para dois anos.

Na prática, migrantes que se encontrem fora do Haiti não podem utilizar esse recurso. Isso pode ser observado no retorno da migração indocumentada de haitianos que residiam no Chile e passaram a entrar no Brasil por meio da cidade de Corumbá, no Mato Grosso do Sul, a partir do primeiro semestre de 2018. De todo modo, as medidas restritivas à migração têm feito os haitianos redirecionarem seus fluxos e suas estratégias de mobilidade, mas não tem impedido a ampliação da sua diáspora.

Frente ao cada vez mais moderno regime de controle da mobilidade humana, migrantes do mundo inteiro recriam estratégias de fuga que são constantemente transformadas. "Os migrantes desenvolvem continuamente táticas de mobilidade temporária e abandonam novas soluções de trânsito assim que são descobertas pelos guardas de fronteira e recodificadas como problemas de segurança nas fronteiras" (PAPADOPOULOS et al, 2008, 166) [Tradução nossa].

No contexto da migração haitiana atual, o uso de aplicativos virtuais presentes nos aparelhos celulares tem funcionado como uma importante ferramenta na transmissão de informações e organização das viagens. Cada vez mais, informações sobre os perigos, custos e contatos estratégicos circulam por essas ferramentas. Por esse motivo, acreditamos que o uso do conceito de redes sociais e suas novas configurações é útil na análise dos deslocamentos atuais de haitianos pois lança luz na compreensão das estratégias de trânsito, além do destino e origem.

As redes sociais na migração historicamente foram analisadas como importantes meios de transmissão de informações entre migrantes e não

ParaOnde!?, Porto Alegre, v.13, n.2, p.75-89, 2020.http://seer.ufrgs.br/paraonde Edição Especial - VII Seminário Internacional de Estudos Fronteriços 
migrantes, desenvolvendo uma espécie de capital social que poderia ser convertido em recurso útil na hora de migrar (DURAND e MASSEY, 2009). Como a principal característica do capital social é a sua convertibilidade, as relações, tecidas em contextos migratórios, geralmente são usadas para propiciar futuras migrações daqueles inseridos nas redes, sejam familiares, amigos ou conterrâneos. Desse modo, as redes sociais podem se transformar em redes migratórias. A rede migratória é um tipo de rede social adaptada ao ato de migrar (SOARES, 2017).

Grande parte da literatura sobre redes sociais e redes migratórias analisa o papel que essas estruturas desempenham na origem e no destino dos migrantes. Seja na escolha dos potenciais migrantes, na preparação das viagens, na aquisição de documentos, até na recepção, acolhida e ajuda nos processos de inserção laboral e social. Entretando, no contexto de migrações realizadas por etapas, os espaços de trânsito têm ganhado importância e as redes sociais entre migrantes têm mostrado intensa atividade, mesmo que sem sempre em formatos visíveis.

Zibechi (1997), ao analisar o movimento estudantil uruguaio nas décadas de 1980 e 1990, notou que as estruturas tradicionalmente responsáveis por ativismos e manifestações foram perdendo espaço para novas formas de organização sem direção ou estatutos. Entidades políticas como sindicatos e grêmios estudantis, com estruturas organizacionais visíveis, deram lugar a manifestações de caráter espontâneo, gestadas de maneiras submersas nos grupos de jovens que se reuniam nas esquinas, nos grupos de rock, no teatro de bairro e nos coletivos de revistas subterrâneas, comuns naquela época. Tais observações levaram o autor a argumentar que muitos dos ativismos que parecem surgir do nada, na verdade foram gestados de maneira submersa, em redes invisíveis para a grande maioria.

Embora com interesses e recursos técnicos muito diferentes, o caráter submerso da comunicação e articulação entre migrantes no contexto atual nos permite uma associação, no formato, entre as redes juvenis, surgidas em contextos marginais, e as redes de migrantes em frequente mobilidade espacial. Em ambos os casos, os interesses comuns colocam em contato pessoas em redes ocultas que podem emergir em determinados momentos. A comunicação instantânea, e invisível, feita pelos migrantes através dos aplicativos de celular, movimenta uma infinidade de redes submersas que quando emergem, em um posto policial ou um terminal rodoviário, por exemplo, parecem surgir do nada.

Nossa pesquisa de campo identificou o uso intensivo dos aparelhos celulares entre os haitianos como ferramenta para transmissão de informações relacionadas à viagem, tanto durante a estadia em Corumbá como no trânsito para a capital Campo Grande. Informações sobre as rotas, as empresas de ônibus, os horários, preços das passagens e pessoas a quem procurar ajuda em caso de necessidade circulam entre os migrantes por meio de redes sociais virtuais. As informações dos primeiros migrantes alimentam as redes e contribuem na diminuição dos custos e dos riscos dos migrantes atuais e futuros.

ParaOnde!?, Porto Alegre, v.13, n.2, p.75-89, 2020.http://seer.ufrgs.br/paraonde Edição Especial - VII Seminário Internacional de Estudos Fronteriços 
A transmissão de informações entre os próprios migrantes, por meio de suas redes sociais, aparentam ter maior capilaridade e confiança dos que aquelas repassadas por agências de viagem ou instituições públicas. Isso sugere que, em contextos de migração indocumentada, como é o caso dos haitianos em trânsito pela Bolívia, as redes visíveis são menos acessadas do que as redes submersas. Isso porque as informações são repassadas através de laços sociais fortes (RAMELLA, 1995). Desse modo, os haitianos, assim como outros migrantes ao redor do mundo, têm recriado suas estratégias de atravessamento de fronteiras e materializado formas de comunicação em rede submersas na maior parte do tempo.

Adicionalmente, as estratégias de trânsito criadas e recriadas pelos haitianos na América do Sul são respostas aos dispositivos dos regimes de controle da mobilidade, efetivados por Estados e sociedades nos espaços de trânsito e de destino desse fluxo. De acordo com Domenech et al (2016), as leis e projetos, considerados "progressistas" em matéria migratória que se aprovaram ou entraram em discussão nos últimos dez anos no subcontinente, obscureceram o debate em torno do viés de securitização e criminalização ainda presente em diversas realidades. Entretanto, o mesmo autor adverte que antigas e novas práticas de controle migratório são mescladas atualmente.

\begin{abstract}
A interseção ou convergência de práticas antigas e novas de controle e vigilância de migração e mobilidade, agora baseadas tanto na "seguridade estatal" quanto na "segurança humana", nos convida a pensar na formação de um regime único de controle da migração, particularmente a migração "irregular" ou "não documentada", no âmbito sul-americano, desenvolvendo uma modalidade diferente daquela dos países centrais devido à sua posição periférica ou semiperiférica no marco do capitalismo global (DOMENECH et al, 2016, p. 2).
\end{abstract}

Nos países da América do Sul, uma série de medidas estatais e não estatais vem sendo implementadas em matéria migratória e refletem uma multiplicidade de estratégias que tentam combinar um discurso de defesa dos direitos humanos com a securitização e criminalização das migrações. Várias dessas medidas impactaram diretamente os haitianos, um dos grupos de maior mobilidade recente no subcontinente. Por isso, o Chile, que outrora foi um dos destinos dos haitianos que deixaram o Brasil, atualmente estimula, direta e indiretamente, esses migrantes a também saírem de lá.

\title{
3. Um outro caminho: do Chile ao Brasil
}

As mudanças na política migratória do governo de Sebastián Piñera, no Chile, impactaram diretamente na migração haitiana. A partir de abril de 2018, o país passou a exigir vistos de turistas para os haitianos, com permanência máxima de 90 dias. Passou também a emitir vistos humanitários de reunião familiar apenas a cônjuges, filhos menores de idade ou filhos estudantes até 24 anos, com um limite máximo anual de 10 mil vistos (CHILE, 2018). Ainda, em outubro do mesmo ano, o governo chileno criou um programa de retorno voluntário, oferecendo transporte de volta ao Haiti, com a condição de não retorno ao Chile durante nove anos. Essas mudanças, além do racismo e

ParaOnde!?, Porto Alegre, v.13, n.2, p.75-89, 2020.http://seer.ufrgs.br/paraonde Edição Especial - VII Seminário Internacional de Estudos Fronteriços 
xenofobia crescentes e a concorrência com a mão de obra dos venezuelanos, impulsionaram a saída de haitianos do Chile em direção ao Brasil.

Segundo informações dos próprios haitianos, relatadas em pesquisa de campo no mês de agosto de 2018, de ônibus, muitos saem de Santiago com destino à cidade de lquique, no norte do país, seguem em direção à fronteira com a Bolívia, onde alguns afirmaram que a cruzaram à pé por caminho alternativo para evitar a polícia migratória, passam pelas cidades de Oruro, Cochabamba, Santa Cruz de La Sierra e, depois de uma longa viagem, chegam à fronteira com o Brasil, entre as cidade de Puerto Quijarro e Corumbá (mapa 1).

\section{Mapa 1: Rotas da migração haitiana do Chile ao Brasil}

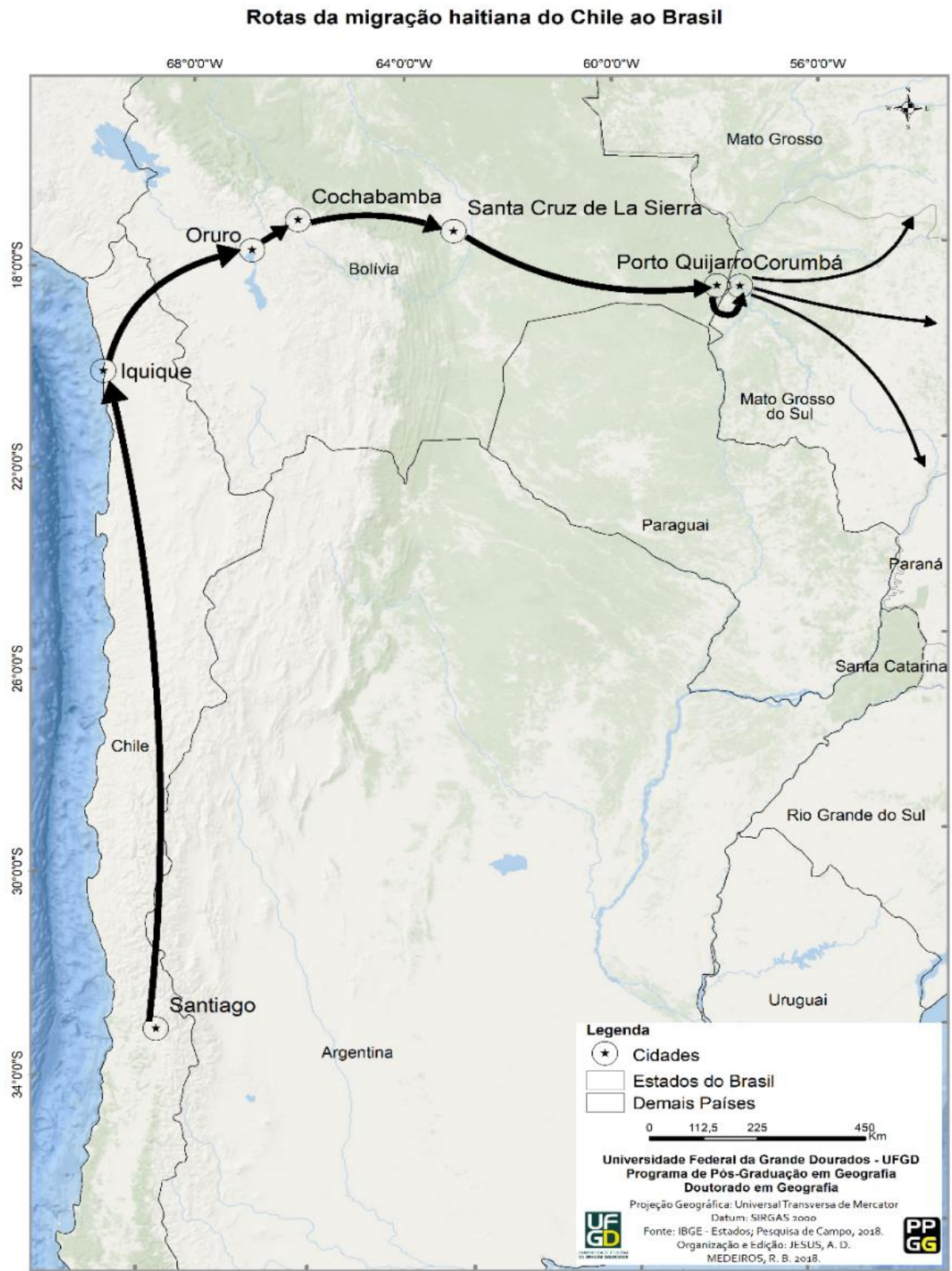

Fonte: próprio autor, 2018.

ParaOnde!?, Porto Alegre, v.13, n.2, p.75-89, 2020.http://seer.ufrgs.br/paraonde Edição Especial - VII Seminário Internacional de Estudos Fronteriços 
Ainda do lado boliviano, taxistas os transportam para a rodoviária de Corumbá, sem passar pelos agentes de migração da Bolívia e do Brasil. Por esse serviço, normalmente é cobrado um preço abusivo de cerca de 20 dólares pelo transporte de alguns quilômetros. Somente no centro da cidade de Corumbá é que eles são orientados a procurarem a Polícia Federal para registrar a entrada. Depois de um agendamento, os haitianos se dirigem ao posto de atendimento na fronteira e, por não portarem o visto humanitário, recebem a notificação de 60 dias para regularizarem a situação migratória ou deixarem o país.

Há também relatos de alguns que alternaram sua viagem entre ônibus e vans orientados por algum agente - ajan ou raketé - para quem eles pagam pela repassam as informações através das redes sociais virtuais, articulando vendedores de passagens, taxistas e até agentes policiais. Em outros casos, há o envolvimento de haitianos residentes no Chile e no Brasil por trás da travessia.

Nossa pesquisa de campo em Corumbá observou que, dentre os haitianos, existiam os agentes que recolhiam o dinheiro para comprar as passagens e/ou pagar hospedagem e alimentação, mas que nem sempre cumpriam com o prometido. Por medo, a maioria evitava falar a respeito do percurso, dos recursos e da organização da viagem. Notamos também, mais de uma vez, que familiares residentes no Brasil se deslocaram para Corumbá a fim de "receber" os recém-chegados. Não sabemos, todavia, as intenções que envolvem essas atitudes.

Em audiência pública convocada pelo Ministério Público Federal e realizada no dia 3 de agosto de 2018 na cidade de Corumbá, a Polícia Federal informou que mais de 1.500 haitianos cruzaram a fronteira Bolívia-Brasil nos sete primeiros meses do ano. A maioria em situação indocumentada, recebendo, portanto, notificação de regularização em 60 dias. Portando esse documento, os haitianos passam a se deslocar para diversos municípios brasileiros, em destaque para a região Sul do país.

Por atravessarem o território boliviano sem visto, esses migrantes tornam-se mais vulneráveis à violências e extorsões. Muitos relatam casos de pagamento de propinas aos policiais, roubos de dinheiro e objetos pessoais. As informações dos próprios migrantes indicam que o tempo de viagem de Santiago até Corumbá gira em torno de uma semana, alguns menos outros mais, a depender dos agentes que organizam a viagem, dos meios de transporte e dos recursos dos próprios haitianos.

A maioria chega em Corumbá sem recursos para seguir viagem para outros destinos no Brasil, sendo obrigados a permanecer na cidade por tempo indeterminado. Além disso, entre os meses de junho e julho, com a chegada diária de dezenas de haitianos, a capacidade da Polícia Federal de emitir as notificações esteve muito abaixo da demanda, o que resultou na permanência de cerca de 400 deles no dia 13 de junho, muitos em situação de rua.

Como o município dispõe de apenas uma casa de abrigo com 22 vagas (figura 1), dividida entre migrantes e moradores de rua, a população local

ParaOnde!?, Porto Alegre, v.13, n.2, p.75-89, 2020.http://seer.ufrgs.br/paraonde Edição Especial - VII Seminário Internacional de Estudos Fronteriços 
passou a abrigá-los em igrejas, hotéis e em casas particulares. A Pastoral da Mobilidade Humana de Corumbá, que já vinha desempenhando ações de acolhida dos haitianos desde o início do ano, passou a articular ações com outros parceiros da sociedade civil a fim de garantir abrigo e alimentação durante o tempo de permanência na cidade.

Figura 1: Quarto na casa de passagem do município de Corumbá

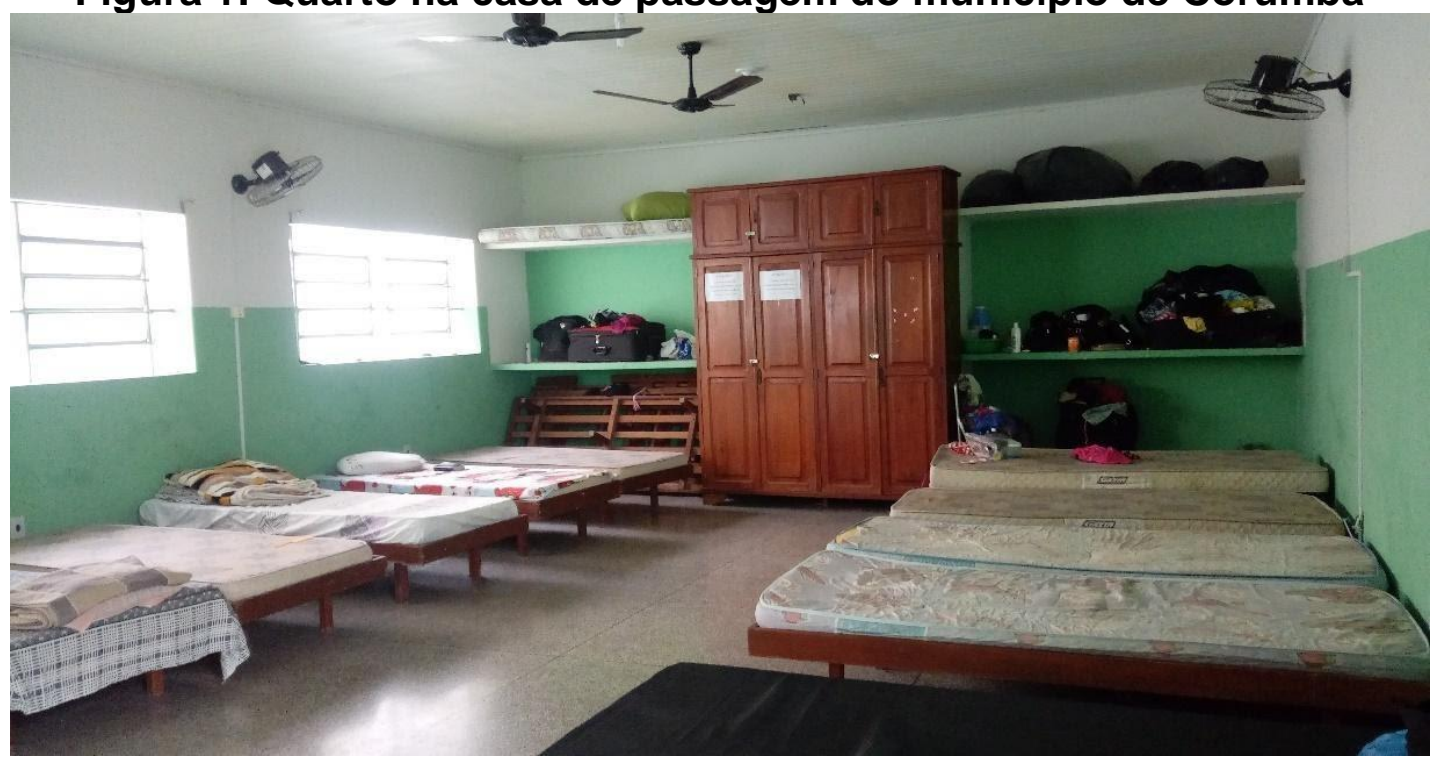

Fonte: próprio autor, 2018.

A omissão do poder público municipal frente à situação fez com que as diversas entidades envolvidas no acolhimento se unissem e criassem o Comitê Humanitário Pantanal Solidário (CHPAS) em junho de 2018. Desde então, as ações emergenciais são articuladas nessa organização, inclusive repartindo os custos entre as entidades parceiras. Isso ilustra que a atuação da sociedade civil, nas fronteiras internacionais ou no interior do Brasil, é reflexo da inexistência de uma política migratória articulada.

Com a intermediação do Ministério Público Federal, a Polícia Federal realizou uma força tarefa no mês de julho de 2018 e emitiu centenas de notificações de regularização para os haitianos. Juntamente com essa ação, voluntários passaram a contribuir com a compra das passagens para aqueles que já não dispunham de recursos. Com isso, o número de haitianos em Corumbá diminuiu, saindo de uma situação de crise, mas mantendo as chegadas diárias de grupos menores.

De acordo com funcionários das empresas de ônibus, as cidades de São Paulo, Curitiba, Chapecó, Cascavel, Toledo, Itajaí e Balneário Camboriú são os principais destinos. Mas há procura para locais bastante variados como Brasília, Contagem e Macapá. Na base dessa mobilidade, estão as redes sociais entre migrantes que se conectam em diversos pontos. A maioria dos que chegam em Corumbá tem pouca ou nenhuma informação sobre o destino e o trajeto da viagem. Dispõem apenas de um número de telefone com quem mantêm contato frequente e o nome da cidade para onde deseja ir.

ParaOnde!?, Porto Alegre, v.13, n.2, p.75-89, 2020.http://seer.ufrgs.br/paraonde Edição Especial - VII Seminário Internacional de Estudos Fronteriços 
Figura 2: Haitianos na Rodoviária de Corumbá

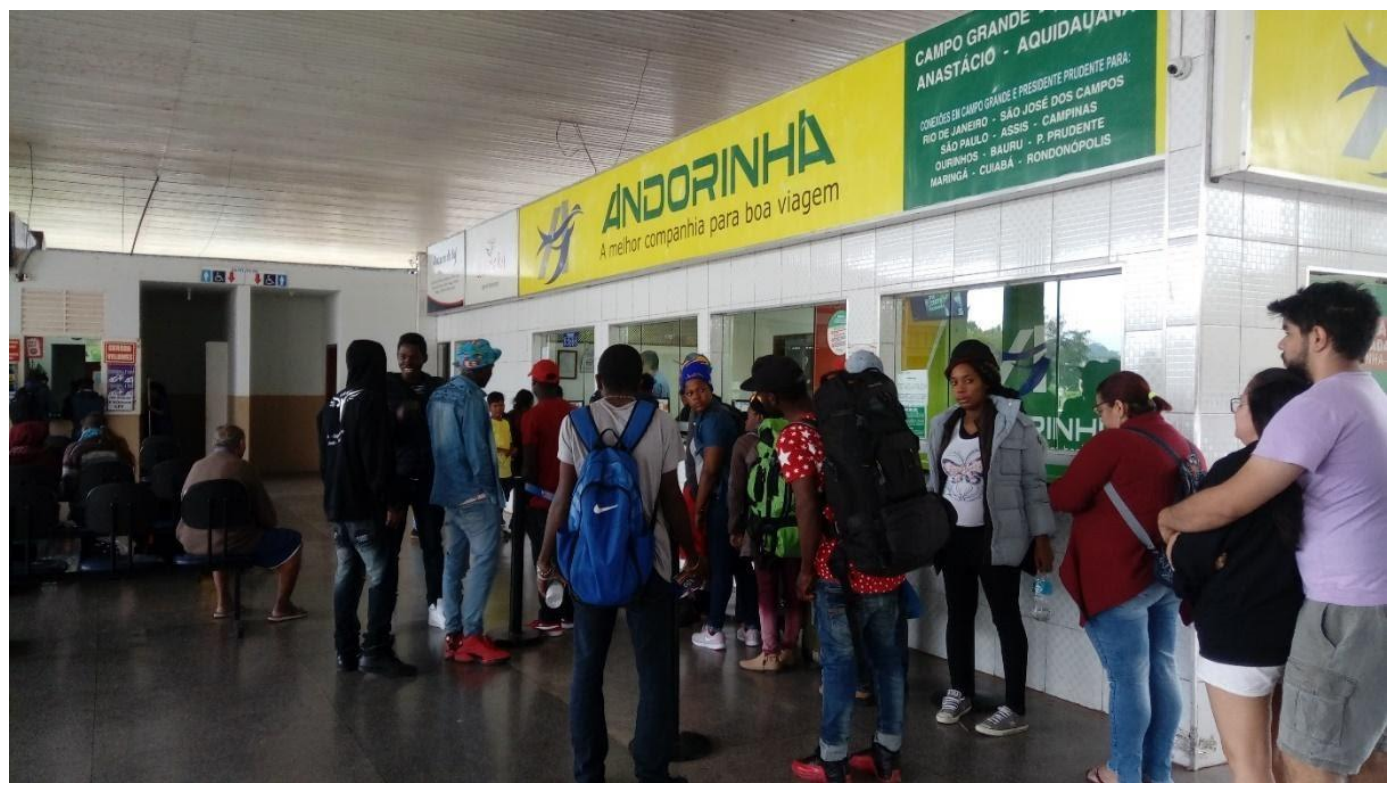

Fonte: próprio autor, 2018.

Durante o ano de 2019, além da continuidade da migração de haitianos do Chile para o Brasil, o município de Bonfim, em Roraima, registou a entrada de mais de 13 mil haitianos vindos da Guiana. Por não exigir vistos de turistas para os haitianos, muitos desembarcam de avião na capital Georgetown e seguem em vans para a cidade de Lethem, na fronteira com o Brasil e seguem para as cidades de Boa Vista e Manaus. Assim como ocorre em Corumbá, essas cidades são locais de passagem para a maioria que se dispersa para uma variedade cada vez maior de municípios brasileiros. Enquanto Corumbá é uma porta de entrada daqueles que estão abandonando o Chile, Bonfim é uma porta de entrada daqueles que vêm diretamente do Haiti. Em ambos os casos, as redes sociais têm operado na base desses processos de mobilidade.

As redes entre migrantes têm sido importantes não apenas nos destinos da migração. Para implementar suas viagens, muitos obtêm recursos de familiares em outras partes do mundo, tendo em vista que as migrações haitianas são antigas e diversificadas e transformaram o Haiti em uma sociedade transnacional (ALFONSO, 2012). Por meio delas, transitam informações e recursos necessários à mobilidade. Quase todos os migrantes que chegam em Corumbá não têm promessas de emprego em seus destinos, mas têm apoio de um amigo ou familiar, o que reduz os custos e os riscos da migração.

As novas tecnologias da informação e comunicação exercem um peso considerável nas migrações atuais. $\mathrm{O}$ constante uso do aparelho celular e 0 acesso à internet intensificam as informações. Sem eles, os atuais trânsitos de haitianos pela América Latina seriam muito mais difíceis. Há rotas mais ou menos definidas, mas uma simples mensagem no celular pode alterá-las ao informar um bloqueio ou uma alternativa menos perigosa, por exemplo.

ParaOnde!?, Porto Alegre, v.13, n.2, p.75-89, 2020.http://seer.ufrgs.br/paraonde Edição Especial - VII Seminário Internacional de Estudos Fronteriços 
Em resposta aos crescentes deslocamentos de população, alguns deles resultados de situações de crise, tem surgido um "giro securitário" que se reflete na proliferação de políticas cada vez mais restritivas à mobilidade. Com reduzidas possibilidades de uma migração documentada e segura, a busca por outras vias, não raras vezes mais perigosas e onerosas, tem sido frequente. Nos parece claro que as medidas restritivas e criminalizantes da migração não tem impedido que ela ocorra, mas tem empurrado os migrantes para alternativas mais arriscadas.

\section{Conclusão}

As precárias condições de vida que seguem presentes no Haiti continuam funcionando como indutores da migração. Além disso, a antiga e intensa saída de haitianos e sua diáspora pelo mundo criou uma densa rede de relações sociais entre o Haiti e os variados destinos. As redes sociais entre migrantes e não migrantes estimulam a continuidade dos fluxos, mais recentemente incorporando países da América do Sul, em destaque para o Chile e o Brasil.

As respostas à mobilidade internacional de haitianos na América do Sul tem sido a implementação de políticas restritivas, o que, em vez de desestimular os migrantes, tem fomentado a migração indocumentada e 0 surgimento de redes de agenciamentos e de tráfico de pessoas. Tais políticas, frequentemente ancoradas em discursos em defesa dos direitos humanos, contribuem para a busca de alternativas fora do amparo legal dos Estados e expõem os migrantes a situações de maior vulnerabilidade em virtude do seu caráter irregular.

Especificamente no contexto chileno, concluímos que as mudanças na política migratória, o desemprego e o racismo são fatores que têm influenciado diretamente na decisão dos haitianos de deixarem o país. Por outro lado, a existência de amigos e familiares residentes em diversos municípios brasileiros tem refletido na escolha dos destinos para uma nova etapa migratória. Porém, as alterações relativas à concessão de vistos humanitários para haitianos pelo governo brasileiro também impuseram dificuldades, o que refletiu na situação indocumentada da maioria dos que chegam.

Além disso, apesar de já terem se passado dez anos desse fluxo migratório no Brasil, da chegada constante de outros grupos de migrantes e de - município de Corumbá se configurar como uma porta de entrada de bolivianos que por décadas se dirigem ao Sudeste do país, o Estado brasileiro continua atuando de maneira pouco eficaz em matéria migratória. Em Corumbá, assim como em outros locais de entrada, o acolhimento dos migrantes fica, quase que exclusivamente, a cargo da sociedade civil e entidades religiosas.

ParaOnde!?, Porto Alegre, v.13, n.2, p.75-89, 2020.http://seer.ufrgs.br/paraonde Edição Especial - VII Seminário Internacional de Estudos Fronteriços 


\section{Referência}

ALARCÓN, Mauricio Burbano. Los Haitianos em Ecuador: uma aproximación desde el acceso a derechos. In: PEDEMONTE, Nicolás Rojas e KOECHLIN, José. (eds.). Migración Haitiana Hacia Sur Andino. Santiago: SJM, 2017. p. 15-40.

ALFONSO, Haroldo Dilla. La migración haitiana en el Caribe: una proposta para la acción. Servicio Jesuita de Migrantes. Santo Domingo, 2012.

AUDEBERT Cédric. The recent geodynamics of Haitian migration in the Americas: refugees or economic migrants? Revista Brasileira de Estudos Populacionais. Belo Horizonte, v.34, n.1, jan./abr. 2017. p. 55-71.

BAENINGER, Rosana et al (Orgs). Imigração Haitiana no Brasil. Jundiaí: Paco Editorial, 2016.

BARRANDEGUY, Tomás. Haitianos, más de 2.500 historias de una comunidad que crece en la ciudad. La Capital, 2017. Disponível em: https://www.lacapital.com.ar/la-ciudad/haitianos-mas-2500-historias-unacomunidad-que-crece-la-ciudad-n1338558.html Acesso feito em: 30/11/2017.

BRASIL. Portaria Interministerial no 10, de 6 de abril de 2018. Disponível em: http://www.in.gov.br/web/guest/materia//asset publisher/Kujrw0TZC2Mb/conten t/id/9580007/do1-2018-04-09-portaria-interministerial-n-10-de-6-de-abril-de2018-9580003 Acesso feito em: 1 de agosto de 2018.

Disponível em:

Portaria Interministerial no 12, de 20 de dezembro de 2019.

http://www.in.gov.br/en/web/dou/-/portaria-interministerial-n-12-de-20-dedezembro-de-2019-234972085 Acesso feito em: 20 de janeiro de 2020.

CALMONT, André. Les Haïtiens en Guyane: une communauté en voie d'intégration? In: Espace, populations, sociétés. 1993. p. 427-434.

CARRERA, Gabriela Bernal. La migración haitiana hacia Brasil: Ecuador, país de tránsito. In: La migración haitiana hacia Brasil: características, oportunidades y desafios. Cuadernos migratorios n6. OIM, 2014.

CHILE. Nueva Ley de Migraciones. Disponível em: https://www.gob.cl/nuevaleydemigracion/ Acesso feito em 23 de agosto de 2018.

DOMENECH, Eduardo, et al. Pasado y presente de las políticas y prácticas de control y vigilancia de la migración en Sudamérica. Editorial. Astrolabio nueva época. ( $\mathrm{n}^{\circ}$ 17), 2016. p. 1-5.

DURAND, Jorge e MASSEY, Douglas. Clandestinos: migración MéxicoEstados Unidos en los albores del siglo XXI. Universidad Autónoma de Zacatecas/Miguel Ángel Porrúa, 2009.

EVANGELISTA, Irene Duffard. Del caribe haitiano a la Argentina: trayectorias de cuerpos en movilidad humana pos terremoto 2010. Buenos Aires: CLACSO, 2016.

ParaOnde!?, Porto Alegre, v.13, n.2, p.75-89, 2020.http://seer.ufrgs.br/paraonde Edição Especial - VII Seminário Internacional de Estudos Fronteriços 
HANDERSON, Joseph. A historicidade da (e)migração internacional haitiana. $O$ Brasil como novo espaço migratório. In: PERIPLOS | GT CLACSO - Migración Sur-Sur| v.1, n.1, p. 7-26, 2017.

PAPADOPOULOS, Dimitris, et al. Escape Routes. Control and Subversion in the Twenty-first Century. Londres: Pluto Press, 2008.

PEDEMONTE, Nicolás Rojas et al. Introducción. In: PEDEMONTE, Nicolás Rojas e KOECHLIN, José. (eds.). Migración Haitiana Hacia Sur Andino. Santiago: SJM, 2017. p. 9-13.

PEDEMONTE, Nicolás Rojas, Nassila AMODE y VÁSQUEZ, Jorge. Migración Haitiana Hacia Chile: origem y aterrizaje de nuevos proyectos migratorios. In: PEDEMONTE, Nicolás Rojas e KOECHLIN, José. (eds.). Migración Haitiana Hacia Sur Andino. Santiago: SJM, 2017. p. 65-162.

RAMELLA, Franco. Por un uso flerte del concepto de red en los estúdios migratórios. In: BJERG, Mária; OTERO, Hernán (Orgs.). Immigración y redes sociales en la Argentina. Buenos Aires: CEMLA Moderna, 1995. pp. 9-21.

SINCRE - Sistema Nacional de Cadastro e Registro de Estrangeiros. OBMIGRA. Microdados 2010-2017. Disponível em: $<$ http://obmigra.mte.gov.br/index.php/microdados>. Acesso feito em 5 de abril de 2018.

SOARES, Weber. Rede Migratória. In: CAVALCANTI, Leonardo et al (Orgs.). Dicionário crítico de migrações internacionais. Brasília: Editora UnB, 2017. pp. 612-615.

VÁSQUEZ, Tania. BUSSE, Erika. y IZAGUIRRE, Lorena. La migración haitiana en Perú y su trânsito hacia Brasil. In: La migración haitiana hacia Brasil: características, oportunidades y desafios. Cuadernos migratorios $\mathbf{n}^{\circ} \mathbf{6}$. OIM, 2014.

VILLANUEVA, Alejandra. Construcción del relato biográfico y proyecciones de vida. Versiones de la migración haitiana en Santiago de Chile. Buenos Aires: CLACSO, 2014. ZIBECHI, Raúl. La Revuelta Juvenil de Los '90. Las redes sociales en la gestación de una cultura alternativa. Montevideu: Nordan-Comunidad, 1997. 